Gut and Liver, Vol. 9, No. 4, July 2015, pp. 534-539

\title{
Different Strategies for Transpancreatic Septotomy and Needle Knife Infundibulotomy Due to the Presence of Unintended Pancreatic Cannulation in Difficult Biliary Cannulation
}

Yoon Jung Lee, Yun Kyung Park, Min Ji Lee, Kyu Taek Lee, Kwang Hyuck Lee, and Jong Kyun Lee

Division of Gastroenterology, Department of Medicine, Samsung Medical Center, Sungkyunkwan University School of Medicine, Seoul, Korea

See editorial on page 435 .

Background/Aims: Several precut techniques have been used to gain biliary access for difficult cases. The aim of this study was to evaluate the success and complication rates of two precut techniques, transpancreatic septotomy (TPS) and needle knife infundibulotomy (NKI), in difficult biliary cannulation due to the presence of unintended pancreatic cannulation. Methods: Eighty-six patients who failed standard biliary cannulation were included. TPS was performed when we failed to achieve biliary access despite 5 minutes of attempted cannulation or when more than three attempted unintended pancreatic cannulations occurred. If deep cannulation was not achieved within 5 minutes for any duct, $\mathrm{NKI}$ was performed. If this failed, we crossed over to the other technique in the second attempt. Results: The initial total success rate of biliary cannulation was $88.4 \%(86.6 \%$ for the TPS group and $94.7 \%$ for the NKI group, $p=0.447$ ). After crossover of the techniques, the final success rate was $95.3 \%$. The complication rate was $20.9 \%$ in patients with TPS and $15.8 \%$ in patients with NKI $(p=0.753)$. Conclusions: The use of different strategies based on the presence of unintended pancreatic cannulation may help increase the success rate for difficult biliary cannulation without increasing complication rates. (Gut Liver 2015;9:534-539)

Key Words: Difficult biliary cannulation; Cholangiopancreatography, endoscopic retrograde; Needle knife infundibulotomy; Transpancreatic septotomy

\section{INTRODUCTION}

Selective biliary cannulation is the most critical step for successful therapeutic biliary endoscopy. The overall success rate of conventional cannulation ranges from 90\% to 95\%, even when performed by experts. ${ }^{1}$ In about $5 \%$ to $10 \%$ of cases, selective biliary cannulation cannot be achieved, necessitating precut sphincterotomy. ${ }^{1-3}$ Several precut techniques have been used to gain biliary access for those difficult cases, particularly according to the presence or absence of unintended repeated pancreatic cannulation.

If unintended pancreatic cannulations are repeated for difficult biliary cannulation, some precut techniques are helpful such as transpancreatic septotomy, the double guide wire method, or pancreatic stenting. In the case of the double guide wire method or pancreatic stenting, additional instruments, time, and cost are notably required. This prompted our interest in transpancreatic septotomy.

The most widely practiced precut technique is needle knife infundibulotomy, which is valuable if biliary cannulation is not achieved for any duct. ${ }^{4}$ The advantage of this technique is that it can minimize the risk of perforation and pancreatitis, due to the predefined upper extent of the cut and untouched pancreatic duct. $^{5}$

The aim of this study was to evaluate the success and complication rates of two precut techniques, transpancreatic septotomy (TPS) and needle knife infundibulotomy (NKI) for difficult biliary cannulation based on the presence of unintended pancreatic cannulation.

\footnotetext{
Correspondence to: Jong Kyun Lee

Division of Gastroenterology, Department of Medicine, Samsung Medical Center, Sungkyunkwan University School of Medicine, 81 Irwon-ro, Gangnam-gu, Seoul 135-710, Korea

Tel: +82-2-3410-3409, Fax: +82-2-3410-6983, E-mail: jongk.lee@samsung.com

Received on June 5, 2014. Revised on August 31, 2014. Accepted on October 25, 2014. Published online May 13, 2015

pISSN 1976-2283 eISSN 2005-1212 http://dx.doi.org/10.5009/gnl14223

@) This is an Open Access article distributed under the terms of the Creative Commons Attribution Non-Commercial License (http://creativecommons.org/licenses/by-nc/4.0) which permits unrestricted non-commercial use, distribution, and reproduction in any medium, provided the original work is properly cited.
} 


\section{MATERIALS AND METHODS}

\section{Patients}

A total of 709 consecutive patients underwent therapeutic endoscopic retrograde cholangiopancreatography (ERCP) by a single experienced pancreatobiliary endoscopist from August 2009 and August 2013 at Samsung Medical Center, Seoul, Korea, and 86 patients were ultimately enrolled in this study (Fig. 1). All ERCPs performed during this time interval were prospectively recorded in an electronic reporting database and reviewed retrospectively. Eligible patients included those who were indicated for therapeutic ERCP with definite indication of biliary access, but failed biliary cannulation despite 5 minutes of attempted cannulation or more than three attempted unintended pancreatic cannulations. Patients were excluded if they had an altered anatomy of the stomach, coagulopathy, previous sphincterotomy or recent pancreatitis. Before ERCP, all patients provided informed consent. This work was approved by the Institutional Review Board of the Samsung Medical Center.

\section{Definitions}

Difficult biliary cannulation was defined as the failure to achieve biliary access despite 5 minutes of attempted cannulation or more than three attempted unintended pancreatic cannulations. $^{6,7}$

The papillary configuration was classified as follows: normal, bulging, redundant, impacted stone, papillitis, peripapillary diverticulum, abnormal location or small orifice. The bulging type showed marked swelling of the oral protrusion of papilla. The redundant type showed the longitudinal shape of the papilla and the orifice located in the lower portion of the papilla. Abnormal location signified the deviated axis of papilla from the 11 to 1 o'clock position or an unusual location of the papilla which was leaning toward the third portion of the duodenum.

The definition and severity of all complications after ERCP were based on consensus criteria. ${ }^{8}$ Mild pancreatitis was defined as abdominal pain with a serum lipase more than 3 times the

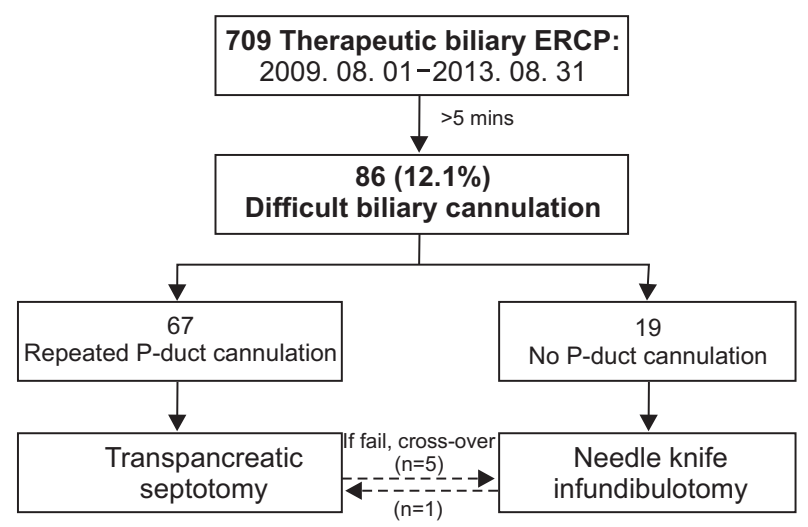

Fig. 1. Flowchart of the study design. ERCP, endoscopic retrograde cholangiopancreatography. upper limit of normal at more than 24 hours after the procedure, requiring admission or prolongation of admission for 2 to 3 days. Moderate pancreatitis required hospitalization for 4 to 10 days, and severe pancreatitis required hospitalization for $>10$ days or if intervention was required, or pseudocyst or hemorrhagic transformation developed. According to the consensus criteria, procedure-related bleeding was defined as mild if hemoglobin drop was $<3 \mathrm{~g} / \mathrm{dL}$, moderate if transfusion of 4 or fewer units was required, and severe if 5 or more units or intervention was required. Cholangitis was defined as mild if temperature was $>38^{\circ} \mathrm{C}$ for 24 to 48 hours, moderate if febrile illness required more than 3 days of hospital treatment or if intervention was required, and severe if septic shock was evident.

\section{Endoscopic procedures}

Midazolam, antispasmodic agents and pethidine, alone or in combination, were administered routinely before the procedure. One experienced pancreatobiliary endoscopist performed all procedures with side-viewing endoscopes (JF-240, JF-260V and TJF-240; Olympus Optical Co., Ltd., Tokyo, Japan). Either MicroKnife $^{\mathrm{TM}}$ XL (Boston Scientific, Natick, MA, USA) or Ultratome ${ }^{\mathrm{TM}}$ XL (Boston Scientific) was used as papillotomes.

Standard biliary cannulation was attempted first. All standard biliary cannulations were performed with a sphincterome preloaded with guidewire for therapeutic purposes. If the biliary cannulation could not be achieved within 5 minutes, the precut technique was used. If biliary cannulation in 5 minutes failed with repeated unintended pancreatic cannulations, TPS was performed. If billiary cannulation was not achieved within 5 minutes for any duct, NKI was performed. If that failed, we crossed over to the other technique in the second attempt.

The TPS was performed with a standard papillotome. After a guidewire had been inserted into the pancreatic duct, a sphincterotomy was performed with a cutting wire along the biliary direction at 11 to 12 o'clock. The incision was made through the septum between the pancreatic and biliary duct until the bile duct orifice was exposed. After the bile duct orifice was exposed, the Ultratome ${ }^{\mathrm{TM}} \mathrm{XL}$ was repositioned to the biliary duct and the sphincterotomy was extended to expose the lumen. Additional sphincterotomy or balloon dilatations were performed for all of the TPS cases.

When the biliary cannulation was not achieved within 5 minutes for any duct, NKI was performed. This technique involves making a puncture into the papilla above the orifice to avoid injuring the pancreatic duct and to minimize the rate of postERCP pancreatitis, which is the most serious complication of such procedures, and then cutting in the 11 to 12 o'clock direction along the ridge of the common bile duct using a needle knife papillotome. After a fistula to the bile duct was made, the standard papillotome was repositioned to the biliary duct and the sphincterotomy was extended. 


\section{Outcomes}

The primary outcome was the success rate of two precut techniques. The secondary outcome was the rates of procedurerelated complications, such as post-ERCP pancreatitis, bleeding, perforation, and cholangitis.

\section{Statistical analysis}

Continuous variables were expressed as medians and ranges, and were analyzed using the Mann-Whitney test, while categorical variables were analyzed with Fischer exact tests. Statistical significance was indicated by a two-tailed p-value of $<0.05$. SPSS software version 20.0 (SPSS Inc., Chicago, IL, USA) was used for statistical analysis.

\section{RESULTS}

\section{Baseline characteristics}

In the study period, 86 of 709 patients met the inclusion criteria and underwent the precut technique procedure. Thus, the success rate of biliary cannulation by conventional cannulation technique was $87.9 \%$.

Patient characteristics of the TPS and NKI groups are summarized in Table 1 . The TPS and NKI groups were comparable in terms of age, sex, indication of ERCP, clinical presentation and preprocedural levels of total bilirubin, alanine transaminase, and alkaline phosphatase. But, the distribution of papilla configuration and location were significantly different in the two groups. In the TPS group, 53.7\% of patients showed the normal configuration of papilla, whereas only $9.0 \%$ of patients showed a bulging configuration. On the other hand, in the NKI group, $42.1 \%$ of patients showed the bulging configuration of papilla, whereas only $10.5 \%$ patients showed a normal configuration (Table 2).

\section{Success rate of biliary cannulation}

Of the 86 patients who needed a precut technique for biliary cannulation, TPS and NKI techniques were performed for 67 patients and 19 patients, respectively.

Fifty-eight patients (86.6\%) from the TPS group had successful cannulations through the bile duct. Of the nine patients who still did not have a successful biliary cannulation after the TPS technique at the first trial, five patients were switched to the NKI technique in the second attempt and successful cannulations were performed in all patients. For the remaining four patients in which the TPS technique did not work initially, NKI could not be attempted due to the relatively small size of the papilla or an unsuitable location or direction of the papilla for infun-

Table 1. Baseline Characteristics of Patients Who Underwent Precut Papillotomy

\begin{tabular}{|c|c|c|c|c|}
\hline Characteristic & TPS $(n=67)$ & NKI $(n=19)$ & Total $(n=86)$ & p-value \\
\hline Age, yr & 68.0 & 66.0 & & 0.958 \\
\hline Male sex & 40 (59.7) & $11(57.9)$ & 51 (59.3) & 1.000 \\
\hline Indications & & & & 0.243 \\
\hline Choledocholithiasis & $30(44.8)$ & $8(42.1)$ & $38(44.2)$ & \\
\hline Malignancy & $26(38.8)$ & $6(31.6)$ & $32(37.2)$ & \\
\hline Post-LT stricture & $3(4.5)$ & $4(21.1)$ & $7(8.1)$ & \\
\hline Bile leak & $4(6.0)$ & 0 & $4(4.7)$ & \\
\hline Benign stricture & $2(3.0)$ & 0 & $2(2.3)$ & \\
\hline Other & $2(3.0)$ & $1(5.3)$ & $3(3.5)$ & \\
\hline Clinical presentation & & & & 0.258 \\
\hline Abdominal pain & $29(43.3)$ & 6 (31.6) & 35 (40.7) & \\
\hline Jaundice & $16(23.9)$ & $8(42.1)$ & $24(28.0)$ & \\
\hline Fever & $3(4.5)$ & $1(5.3)$ & $4(4.7)$ & \\
\hline Charcot's triad & $6(9.0)$ & $3(15.8)$ & $9(10.5)$ & \\
\hline Other & $13(19.4)$ & $1(5.3)$ & $14(16.3)$ & \\
\hline Total bilirubin, mg/dL & 2.5 & 3.4 & 2.6 & 0.368 \\
\hline ALT, U/L & 73.0 & 141.0 & 81.5 & 0.325 \\
\hline ALP, U/L & 181.0 & 134.0 & 150.5 & 0.651 \\
\hline \multicolumn{5}{|l|}{ Premedication } \\
\hline Protease inhibitor & $26(38.8)$ & $9(47.4)$ & 35 (40.7) & 0.599 \\
\hline
\end{tabular}

Data are presented as number (\%) or mean.

TPS, transpancreatic septotomy; NKI, needle knife infundibulotomy; LT, liver transplantation; ALT, alanine aminotransferase; ALP, alkaline phosphatase. 
Table 2. Papillary Configurations of Patients Who Underwent Transpancreatic Septotomy and Needle Knife Infundibulotomy

\begin{tabular}{|c|c|c|c|c|}
\hline & TPS $(n=67)$ & NKI $(n=19)$ & Total $(n=86)$ & p-value \\
\hline Papilla configuration/location & & & & 0.001 \\
\hline Normal & $36(53.7)$ & $2(10.5)$ & $38(44.2)$ & 0.001 \\
\hline Bulging & $6(9.0)$ & $8(42.1)$ & $14(16.3)$ & 0.002 \\
\hline Redundant & $11(16.4)$ & $2(10.5)$ & $13(15.1)$ & 0.724 \\
\hline Impacted stone & $1(1.5)$ & $1(5.3)$ & $2(2.3)$ & 0.395 \\
\hline Papillitis & $4(6.0)$ & $2(10.5)$ & $6(7.0)$ & 0.610 \\
\hline Peripapillary diverticulum & $4(6.0)$ & $2(10.5)$ & $6(7.0)$ & 0.610 \\
\hline Abnormal location & $4(6.0)$ & $2(10.5)$ & $6(7.0)$ & 0.610 \\
\hline Small orifice & $1(1.5)$ & 0 & $1(1.2)$ & 1.000 \\
\hline
\end{tabular}

Data are presented as number (\%).

TPS, transpancreatic septotomy; NKI, needle knife infundibulotomy.

Table 3. Success Rate of Transpancreatic Septotomy and Needle Knife Infundibulotomy

\begin{tabular}{lcccc}
\hline & TPS $(\mathrm{n}=67)$ & NKI $(\mathrm{n}=19)$ & Total $(\mathrm{n}=86)$ & $\mathrm{p}$-value \\
\hline First trial & $58 / 67(86.6)$ & $18 / 19(94.7)$ & $76 / 86(88.4)$ & 0.447 \\
Final & $63 / 67(94.0)$ & $19 / 19(100.0)$ & $82 / 86(95.3)$ & \\
\hline
\end{tabular}

Data are presented as number (\%).

First trial: success rate of first trial, by intention-to-treat approach. Final: success rate after crossover to the other technique. NKI $\rightarrow$ TPS $1 / 1(100 \%)$, TPS $\rightarrow$ NKI 5/5 (100\%).

TPS, transpancreatic septotomy; NKI, needle knife infundibulotomy.

dibulotomy. Of these four patients, one patient was successfully cannulated during the second ERCP. The remaining three patients underwent percutaneous transhepatic biliary drainage procedures.

Eighteen patients (94.7\%) from the NKI group were successfully cannulated on the first attempt. For the one patient that was not successfully cannulated during the first trial, we crossed over to the TPS technique for the second attempt, which resulted in a successful biliary cannulation.

The success rates between TPS and NKI were not statistically different at the first trial $(86.6 \%$ vs $94.7 \%, p=0.447)$ or after cross-over (94.0\% vs 100.0\%) (Table 3).

\section{Complications}

The overall incidence of post-ERCP pancreatitis was 10.4\% $(7 / 67)$ in the TPS group and 5.3\% (1/19) in the NKI group. In all cases, the severity of post-ERCP pancreatitis was mild and patients recovered within a few days. There was no statistically significant difference between the two groups.

Procedure-related bleeding developed in five patients in the TPS group (7.5\%) and one patient in the NKI group (5.3\%). The severity of the bleeding case in the NKI group was severe, while all five cases of the TPS group were mild. Only one episode of perforation occurred in the NKI group, but it was a microperforation and the patient was cured with conservative treatment within 1 week. Post-ERCP cholangitis occurred in only two
Table 4. Complication Rates of Transpancreatic Septotomy and Needle Knife Infundibulotomy

\begin{tabular}{lcccc}
\hline & TPS $(\mathrm{n}=67)$ & NKI $(\mathrm{n}=19)$ & Total $(\mathrm{n}=86)$ & $\mathrm{p}$-value \\
\hline Complication rate & $14 / 67(20.9)$ & $3 / 19(15.8)$ & $17 / 86(19.8)$ & 0.753 \\
Pancreatitis & $7 / 67(10.4)$ & $1 / 19(5.3)$ & $8 / 86(9.3)$ & 0.678 \\
$\quad$ Mild & 7 & 1 & 8 & \\
$\quad$ Moderate & 0 & 0 & 0 & \\
$\quad$ Severe & 0 & 0 & 0 & \\
Bleeding & $5 / 67(7.5)$ & $1 / 19(5.3)$ & $6 / 86(7.0)$ & 1.000 \\
$\quad$ Mild & 5 & 0 & 5 & \\
$\quad$ Severe & 0 & 1 & 1 & \\
Perforation & $0 / 67$ & $1 / 19(5.3)$ & $1 / 86(1.2)$ & 0.221 \\
Cholangitis & $2 / 67(3.0)$ & $0 / 19$ & $2 / 86(2.3)$ & 1.000 \\
\hline
\end{tabular}

Data are presented as number (\%).

TPS, transpancreatic septotomy; NKI, needle knife infundibulotomy.

patients of the TPS group (3.0\%) and the severity of cholangitis in the two cases was moderate. There were no statistically significant differences between the two groups in the rates of procedure-related bleeding, perforation, and post-ERCP cholangitis (Table 4).

\section{DISCUSSION}

Selective biliary cannulation is the most critical step for successful therapeutic biliary endoscopy during ERCP. The overall success rate of conventional cannulation ranges from 90\% to 95 $\%$ and in the remaining cases, a precut technique is needed. ${ }^{1-3}$ AS in any other interventional procedure, precut techniques are accompanied by some complications, such as post-ERCP pancreatitis, procedure-related bleeding, perforation or post-ERCP cholangitis. But, difficult cannulations associated with the delay of precut techniques can be independent risk factors for postERCP pancreatitis, because repeated attempts of cannulation may cause mechanical trauma, edema, or inflammation., ${ }^{9,10}$ So, it is very important to determine the proper timing of precutting 
and the proper technique. Though there is no consensus criteria for difficult cannulation, we defined difficult biliary cannulation as a failure to achieve biliary access despite 5 minutes of attempted cannulation or more than three attempted unintended pancreatic cannulations. ${ }^{6,7}$ The criteria were stricter than previous reports which defined difficult cannulation as the failure to achieve biliary access despite 10 minutes of attempted cannulation, or more than five attempted unintended pancreatic cannulations, to avoid unsuccessful repeated cannulation and reduce procedure-related complications. In our study, the success rate of biliary cannulation by the conventional cannulation technique was slightly lower than in previous reports (87.9\% vs 90\%-95\%). The stricter definitions of difficult cannulation could be a possible explanation of the lower success rate.

If unintended pancreatic cannulations are repeated, the TPS technique could be helpful. The TPS technique was first described in $1995 .{ }^{11}$ This technique is superior to other precut techniques, such as double guide wire method or pancreatic stenting, in that it requires no additional instruments, time, or costs.

In cases where biliary cannulation is not achieved for any duct, the most widely practiced precut technique is using a needle knife. ${ }^{4}$ The needle knife technique was first described in the early 1980s and has since been commonly performed. ${ }^{2}$ Precut sphincterotomy with a needle knife is performed either by a precut papillotomy or by infundibulotomy. In the papillotomy technique, the incision starts from the papillary orifice, whereas in the fistulotomy technique, the incision starts above the papillary orifice. Although the precut papillotomy may improve the cannulation success rate, prospective studies have suggested that it is an independent risk factor for post-ERCP complications. $^{5,12}$

In this study, we aimed to evaluate our strategy, which applies different precut techniques based on the presence of unintended pancreatic cannulation, instead of only comparing NKI and TPS in difficult biliary cannulation. The success rate of the two precut techniques was superior to those reported in other studies using NKI or TPS, alone or in comparison of both. ${ }^{2,11,13-16}$ We believe that the higher success rate of our study is based on our strategy map. In most of the previously published reports, the patients were randomized to one of the different precut groups and the success rate of the precut technique was reviewed retrospectively. In contrast, we prospectively assigned the patients to the different precut technique groups based on the presence of unintended pancreatic cannulation and then reviewed the results retrospectively. The other critical factor of the higher success rate of our study is the cross-over strategy. Wang et al. ${ }^{16}$ aimed to compare the success and the complication rates of TPS with needle-knife sphincterotomy (papillotomy). The specific precut techniques undertaken depended on the endoscopist's preference and the presence of unintended pancreatic cannulation. In cases where the first biliary cannulation failed after precut sphincter- otomy, ERCP was repeated within 2 to 5 days using a standard cannulation technique without precut. This differs from our cross-over strategy approach. The eventual success rate of TPS and needle-knife papillotomy was $82.9 \%$ and $90.8 \%$, respectively. ${ }^{16}$ In our study, the success rates of fist attempt of TPS and NKI were $86.6 \%$ and $94.7 \%$, respectively. After cross-over to another precut technique for a second attempt, the success rates were $94.0 \%$ and $100.0 \%$, respectively. The eventual success rate of our strategy was superior to the others, which applied the same precut technique or standard cannulation technique in the second attempt. ${ }^{16-19}$

In the TPS group, the success rate of biliary cannulation was similar or slightly higher than in previous reports, whereas the success rate in the NKI group was greatly superior. We could explain the difference based on the baseline characteristics. In our study, both groups were comparable in terms of their baseline characteristics, such as gender, age, ERCP indication, clinical presentation, and the baseline biochemical values of liver function. The only significant difference was the configuration of the papilla (Table 2). In the NKI group, the bulging configuration of the papilla was most frequent, whereas a normal configuration was the most frequent in the TPS group. This difference of papilla configuration could affect the unintended pancreatic cannulation and the eventual success rate of precut techniques. In practice, the bulging type of papilla was a good candidate for an infundibulotomy or the modified techniques of needle knife precut. $^{20}$ So, future studies should examine the adoption of precut method based on papillary configuration in difficult biliary cannulation.

The overall incidence of post-ERCP pancreatitis was $10.4 \%$ $(7 / 67)$ in the TPS group and 5.3\% (1/19) in the NKI group, which were not different from previous studies. ${ }^{13,14,16,21}$ In the NKI group, the rate of post-ERCP pancreatitis was lower than in the TPS group, but there was no statistically significant difference between the two groups. A lower, statistically different, rate of post-ERCP pancreatitis in the NKI group compared to the TPS group was reported. The difference was explained as an avoidance of thermal injury, resulting in complete papilla opening and edema during the procedure, preserving pancreatic flow after the cannulation. ${ }^{13}$

We observed six cases of procedure-related bleeding, one case of microperforation and two cases of moderate cholangitis, all of which showed no statistically significant differences between the two groups. However, due to the small cohort and the small number of incidences of these complications, the frequency of the bleeding, perforation, and cholangitis was inadequate for comparison. Our strategy, which applied the different precut techniques for difficult cannulation based on the presence or absence of unintended pancreatic cannulations, did not increase the rate of post-ERCP complications. However, more large-scale studies are needed to compare the frequency of the bleeding, perforation, and cholangitis between the TPS and NKI groups. 
The limitation of this study was the small number of enrolled patients. Only 86 patients were enrolled and these patients were divided into two unequal groups. This small cohort and disproportionate allocation might influence the interpretation of the success and complication rates of the two precut techniques for difficult biliary cannulation. Therefore, further large-scale studies are needed to overcome this limitation.

In conclusion, the application of different strategies based on the presence of unintended pancreatic cannulations may aid in increasing the success rate for difficult biliary cannulation without increasing complication rates.

\section{CONFLICTS OF INTEREST}

No potential conflict of interest relevant to this article was reported.

\section{REFERENCES}

1. Huibregtse K, Kimmey MB. Endoscopic retrograde cholangiopancreatography, endoscopic sphincterotomy and endoscopic biliary and pancreatic drainage. In: Yamada T, Alpers DH, Powell DW, eds. Textbook of gastroenterology. 2nd ed. Philadelphia: Lippincott, 1995: 2590-2617.

2. Siegel JH. Precut papillotomy: a method to improve success of ERCP and papillotomy. Endoscopy 1980;12:130-133.

3. Huibregtse K, Katon RM, Tytgat GN. Precut papillotomy via fineneedle knife papillotome: a safe and effective technique. Gastrointest Endosc 1986;32:403-405.

4. Udd M, Kylänpää L, Halttunen J. Management of difficult bile duct cannulation in ERCP. World J Gastrointest Endosc 2010;2:97-103.

5. Masci E, Mariani A, Curioni S, Testoni PA. Risk factors for pancreatitis following endoscopic retrograde cholangiopancreatography: a meta-analysis. Endoscopy 2003;35:830-834.

6. Kaffes AJ, Sriram PV, Rao GV, Santosh D, Reddy DN. Early institution of pre-cutting for difficult biliary cannulation: a prospective study comparing conventional vs. a modified technique. Gastrointest Endosc 2005;62:669-674.

7. Lee TH, Hwang SO, Choi HJ, et al. Sequential algorithm analysis to facilitate selective biliary access for difficult biliary cannulation in ERCP: a prospective clinical study. BMC Gastroenterol 2014;14:30.

8. Cotton PB, Lehman G, Vennes J, et al. Endoscopic sphincterotomy complications and their management: an attempt at consensus. Gastrointest Endosc 1991;37:383-393.
9. Freeman ML, DiSario JA, Nelson DB, et al. Risk factors for postERCP pancreatitis: a prospective, multicenter study. Gastrointest Endosc 2001;54:425-434.

10. Vandervoort J, Soetikno RM, Tham TC, et al. Risk factors for complications after performance of ERCP. Gastrointest Endosc 2002;56:652-656.

11. Goff JS. Common bile duct pre-cut sphincterotomy: transpancreatic sphincter approach. Gastrointest Endosc 1995;41:502-505.

12. Freeman ML, Nelson DB, Sherman S, et al. Complications of endoscopic biliary sphincterotomy. N Engl J Med 1996;335:909-918.

13. Katsinelos P, Gkagkalis S, Chatzimavroudis G, et al. Comparison of three types of precut technique to achieve common bile duct cannulation: a retrospective analysis of 274 cases. Dig Dis Sci 2012;57:3286-3292.

14. Catalano MF, Linder JD, Geenen JE. Endoscopic transpancreatic papillary septotomy for inaccessible obstructed bile ducts: comparison with standard pre-cut papillotomy. Gastrointest Endosc 2004;60:557-561.

15. Halttunen J, Keränen I, Udd M, Kylänpää L. Pancreatic sphincterotomy versus needle knife precut in difficult biliary cannulation. Surg Endosc 2009;23:745-749.

16. Wang P, Zhang W, Liu F, et al. Success and complication rates of two precut techniques, transpancreatic sphincterotomy and needle-knife sphincterotomy for bile duct cannulation. J Gastrointest Surg 2010;14:697-704.

17. Yoo YW, Cha SW, Lee WC, Kim SH, Kim A, Cho YD. Double guidewire technique vs transpancreatic precut sphincterotomy in difficult biliary cannulation. World J Gastroenterol 2013;19:108114.

18. Chan CH, Brennan FN, Zimmerman MJ, Ormonde DG, Raftopoulos SC, Yusoff IF. Wire assisted transpancreatic septotomy, needle knife precut or both for difficult biliary access. J Gastroenterol Hepatol 2012;27:1293-1297.

19. Park CS, Park CH, Koh HR, et al. Needle-knife fistulotomy in patients with periampullary diverticula and difficult bile duct cannulation. J Gastroenterol Hepatol 2012;27:1480-1483.

20. Saritas U, Ustundag Y, Harmandar F. Precut sphincterotomy: a reliable salvage for difficult biliary cannulation. World J Gastroenterol 2013;19:1-7.

21. Mavrogiannis C, Liatsos C, Romanos A, Petoumenos C, Nakos A, Karvountzis G. Needle-knife fistulotomy versus needle-knife precut papillotomy for the treatment of common bile duct stones. Gastrointest Endosc 1999;50:334-339. 